\title{
Laser hardening of steel sintered parts
}

\author{
P. Veronesi, R. Sola, E. Colombini, R. Giovanardi \\ Department of Engineering Enzo Ferrari \\ University of Modena and Reggio Emilia \\ Italy
}

\author{
G. Parigi \\ Stav \\ Barberino del Mugello (FI) \\ Italy
}

\begin{abstract}
The possibility of applying rapid and localized laser hardening to near-net shape parts, like the ones deriving from powder metallurgy $(\mathrm{P} / \mathrm{M})$ is investigated, demonstrating that even low alloyed steels $(\mathrm{Fe}+2 \% \mathrm{Cu}+0,7 \% \mathrm{C})$ can be successfully heat treated with minimal or no dimensional variations. Laser hardening conditions have been selected on the basis of the results of the previous research, carried out by means of an Nd-YAG high power system [1]. To avoid some carbon loss, observed on previous activities, the samples have been protected by neutral atmosphere. The microstructural features of the laser hardened steels have been analyzed by optical microscopy, whereas the surface micro-geometry has been characterized by scanning electron microscope. Hardened depth (HD), hardened width (HW) and hardened area (HA) have been measured as well. As expected, the micro-hardness profiles present a sharp drop at low distance from the hardened surface. The typical splitting between hardened zone and heat-affected zone (HAZ), well known from laser hardened fully dense steels, has been observed also on low-alloy sintered steels. The use of a protective atmosphere has been helpful to control surface decarburization and to prevent oxidation. The research confirm that Laser transformation Hardening (LTH) is a suitable hardening process of $\mathrm{P} / \mathrm{M}$ components, through the action of a scanning laser beam. The short heating time and the modest volume fraction structurally modified can contribute to avoid part distortion, in comparison with other hardening methods.
\end{abstract}

Keywords- PM-steel, laser hardening, microstructure, nanoindentation, microhardness

\section{INTRODUCTION}

Laser hardening is an effective surface engineering technique with high rates of heat generation and processing speed that improves surface properties of treated steels as reported by Y. X. Wang et al in [1]. E. Colombini et al in [2]. Laser hardening can play also an important role in duplex treatment, for instance applying laser treatment after plasma nitriding to improve wear properties and penetration depth of $40 \mathrm{CrMnMo} 7$ steels. Depending on the laser processing conditions, laser treatment decreases surface porosity of nitrided layer, increasing nano-mechanical properties of 42CrMo4 gas nitrided steels, as reported by D. Panfil et al. in [3]. Moreover, laser hardening is one of the most promising techniques to obtain a hardened layer with sufficient thickness, ideal fatigue and wear resistance and it does not require cooling fluids (often water- or oil- based), which are potential sources of surface degradation as well as of health and environmental hazards. Laser hardening uses the heat transfer from a very limited laser-heated portion of the material to achieve the desired quenching, not requiring cooling fluids, hence the resulting parts are completely clean, with further advantages in terms of post-processing, storage and costs (the cost associated with preparation, maintenance and disposal of fluids are estimated to amount to $16 \%$ of total manufacturing costs [4]).

Hardening of $\mathrm{P} / \mathrm{M}$ steels by fast laser heating and selfcooling has already been tested successfully by Rowshan, [5], on nearly eutectoidic plain alloy, by Rodziňác et al., [6], on high carbon $\mathrm{Cr}$-alloyed grades, with quenching in a protective argon gas streaming at $15 \mathrm{l} / \mathrm{min}$., and by Bocchini et al., [7-8] on homogeneous or not homogeneous materials, [7-9], based on fully Cr-prealloyed materials or on diffusion-bonded powders. Such works all confirm the suitability of application of laser-processing to $\mathrm{P} / \mathrm{M}$ steel hardenability. However, the possibility of increasing hardness and wear resistance of some "less noble" P/M steels could represent an interesting field of application, coupling localized heat treatments with near net shape products. In this paper the response of $\mathrm{Fe}+2 \% \mathrm{Cu}+$ $0,7 \% \mathrm{C} \mathrm{P} / \mathrm{M}$ parts is investigated using nanoindentation.

\section{EXPERIMENTAL TECHNIQUES}

The sample for the investigation are $\mathrm{P} / \mathrm{M}$ parts deriving from normal large scale production, kindly supplied by the company Stame (Arosio, CO, Italy) and visible in Fig. 1. The powder mix composition is $\mathrm{Fe}+2 \% \mathrm{Cu}+0,7 \% \mathrm{C}$; compaction density resulted $6.6 \div 6.75 \mathrm{~g} / \mathrm{cm}^{3}$ and sintering has been carried out at $1160{ }^{\circ} \mathrm{C}$, under $90 / 10 \mathrm{~N}_{2} / \mathrm{H}_{2}$ atmosphere, with 0.5 ${ }^{\circ} \mathrm{C} / \mathrm{s}$ cooling rate. The laser hardening test have been carried out by the company STAV, (Barberino del Mugello, FI, Italy), using a laser head mounted on an anthropomorphic robot, shown in Fig. 2. Laser hardening has been performed by $4 \mathrm{~kW}$ (maximum power) laser diodes variable power applied continuously, driven by a robot, to process the surface layers of the previously nitrided samples with only single pass heat treatment. The laser source is controlled in terms of surface temperature of the exposed material, measured by means of an optical pyrometer positioned on the laser head. The laser control system automatically changes the emitted power in order to achieve the desired temperature level in the processing zone. This feature is particularly useful because for small samples the average sample temperature is expected to increase during processing, from the beginning to the end of the laser track, since heat from laser source is transferred to the specimen. Laser hardening has been conducted using a straight line passing through one diameter of the sample surface. Based on previous results [5-7], laser hardening parameters have been 
chosen as shown in Table I. The laser hardening system is operated in temperature control, hence source power is variable throughout the treatment. Peak temperature of $1200^{\circ} \mathrm{C}$ has been selected, using $250 \mathrm{~mm}$ as laser focal length. Samples of the "A" and "B" series have been treated under a protective argon atmosphere, while the "nA" and "nB" series have been processed in air, for the comparison's sake and to confirm that the selected workpiece distance from the laser head and the emitting inert gas system are large enough to make negligible any possible cooling effects by forced convection.

The energy density (ED) of the radiation, as described by Babu [9], may be varied by defocussing the beam, i.e., through a displacement of the irradiated surface by a certain distance from the focal plane of the laser objective lens. The laser heat treatment is a localized heat treatment process exploiting relatively low values of energy density (to avoid surface melting). The calculation of energy density $\left[\mathrm{kJ} / \mathrm{mm}^{2}\right]$ is based on the Eq. (1):

$$
\mathrm{ED}=\mathrm{P} / \mathrm{Dv}
$$

where $\mathrm{P}[\mathrm{kW}]$ is the laser beam power, $\mathrm{D}[\mathrm{mm}]$ is the spotdiameter and $v[\mathrm{~mm} / \mathrm{s}]$ is the travel speed of the beam. Table II shows the averaged ED values obtained.

Table I - Laser hardening tests

\begin{tabular}{|c|c|c|c|}
\hline test code & laser beam speed $[\mathbf{m m} / \mathbf{s}]$ & Spot size $[\mathbf{m m x m m}]$ & atmosphere \\
\hline 1A & 8 & $7 \times 7$ & Air \\
\hline 2A & 6 & $7 \times 7$ & Air \\
\hline 1B & 8 & $5 \times 5$ & Air \\
\hline 2B & 6 & $5 \times 5$ & Air \\
\hline A & 8 & $5 \times 5$ & Argon \\
\hline B & 6 & $7 \times 7$ & Argon \\
\hline
\end{tabular}

Table II - Average energy density values

\begin{tabular}{|c|c|}
\hline Sample Code & ED $\left[\mathbf{J} / \mathbf{c m}^{2}\right]$ \\
\hline $1 \mathrm{~A}$ & 1.43 \\
\hline $2 \mathrm{~A}$ & 1.90 \\
\hline 1B & 1.50 \\
\hline 2B & 2.00 \\
\hline B & 1.50 \\
\hline A & 1.90 \\
\hline
\end{tabular}

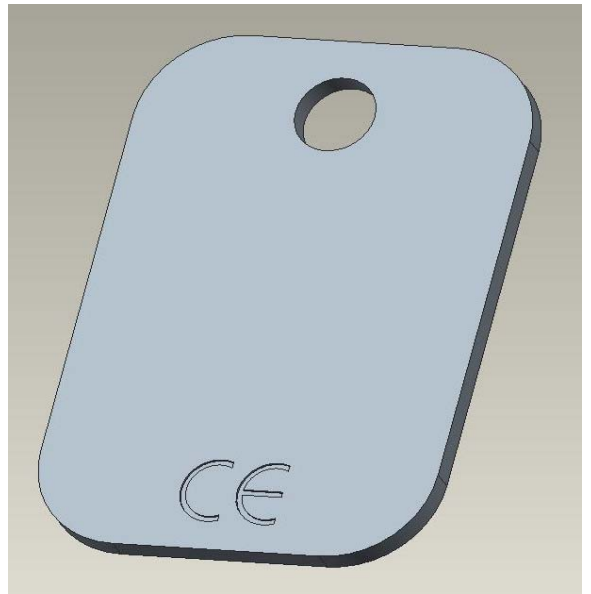

Fig. 1 Samples geometry

Samples $1 \mathrm{~A}$ and B, and 2A and B get the same energy density because the same the same process parameters have been set and the different is only due to the process atmosphere.

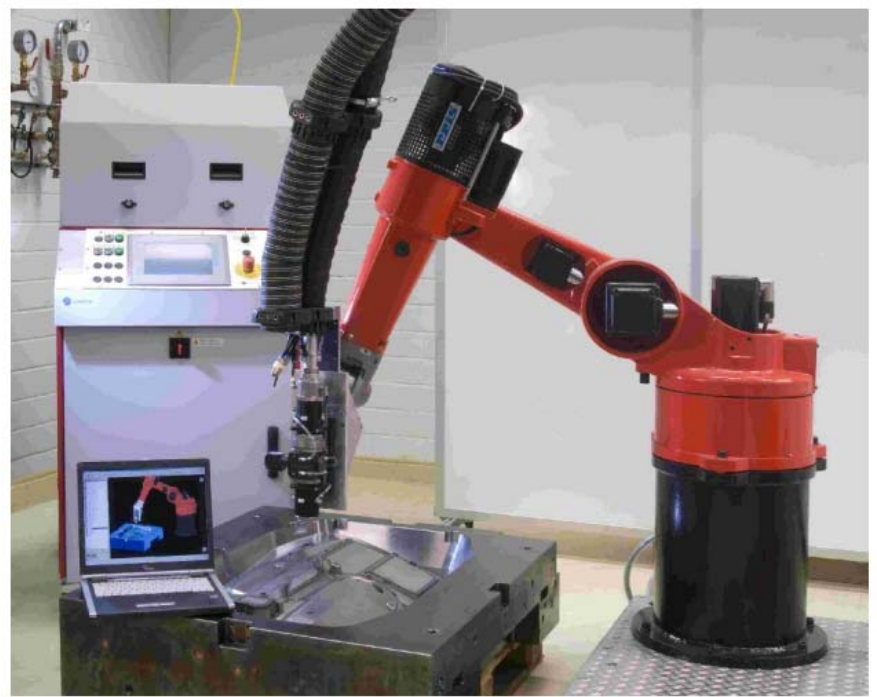

Fig. 2 Laser hardening robot in STAV (Barberino del Mugello, FI, Italy)

The characterization of test samples has been made by:

- optical microscopy for determination of geometry of hardened profiles and microstructural analysis

- SEM observations of microstructure at very high magnification

- microhardness (HV0.1) profile orthogonally to the outer surface, at the center

- nanomechanical testing to investigate nanomechanical properties (hardness, Young's modulus).

Nanoindentation tests have been performed on the surface of the samples using a CSM Nanoindenter equipped with a Berkovich diamond tip. The maximum load was $30 \mathrm{mN}$ and the resolution of displacement $1 \mathrm{~nm}$. During the test, 
the nanoindenter records the penetration depth, $h$, and the load, $w$. The slope $d w / d h$ of the unloading curve at the beginning of unloading can be used to measure $\mathrm{E}$ as described by G. E. Fougere et al in [10], H. T. Chen et al. in [11] and S. K. Balijepalli et al in [12]. Other details of nanoindentation test are given by R. Sola et al. in [13].

\section{RESULTS AND DISCUSSION}

Fig. 3 shows a typical image of a laser hardened zone. The laser hardened regions follow the usual pattern describable as a segment of circle. The analysis of microstructure shows that, on all samples, laser hardening forms martensite near the surface. The samples treated in air exhibit low carbon martensite just below the surface, due to the expected moderate carbon loss. Fine martensite is visible under the decarburized zone, and in Fig. 4 a SEM-BSE microstructure is reported. Independently on the processing conditions tested, martensite prevails up to $0.5 \mathrm{~mm}$ distance from the outer surface. No relevant microstructural difference, as a function of processing atmosphere, has been observed in the sub-superficial layers, thus confirming the negligible cooling effect of the Ar fluxing.

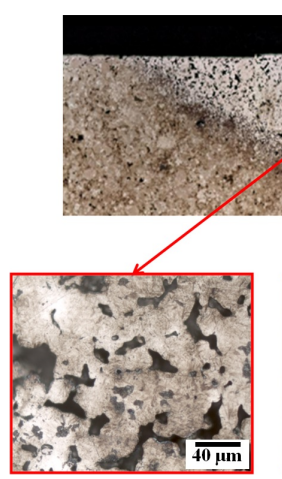

sub-surface zone

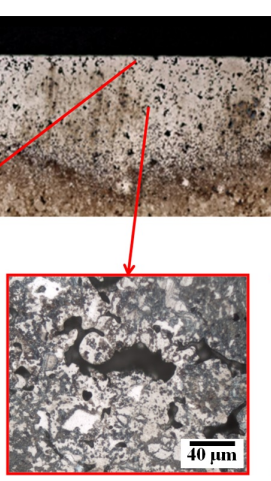

mid-height zone

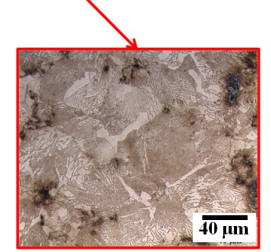

far from heat treated area mid-height zone
Fig. 3 Typical pattern of hardened regions. Cross section perpendicular to the laser advancement line

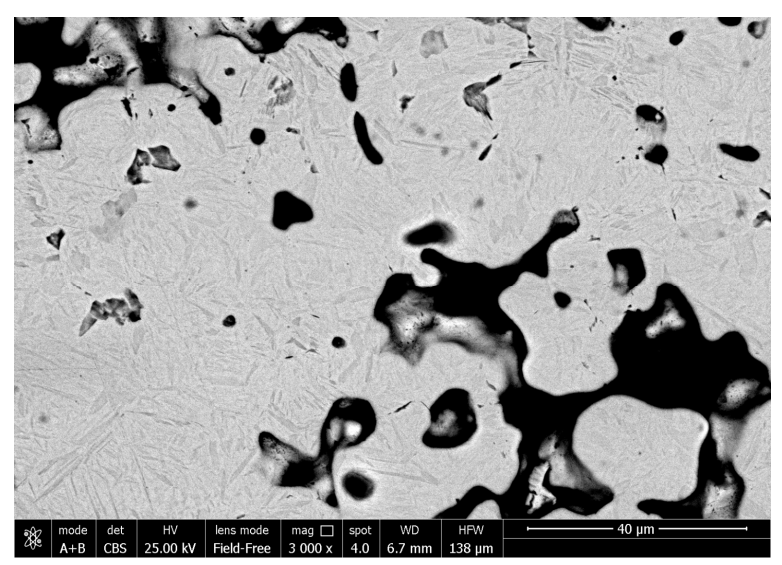

Fig. 4 SEM-BSE micrograph. Martensite in sub-surface zone
As a matter of fact, at mid height of the hardened zones, on all the samples, martensite and lower bainite are present (Fig. $5)$; upper bainite, very fine pearlite and ferrite are visible in the thin transition zones (Fig. 6). Fig. 7 shows the core microstructure, not altered by laser heat treatment, composed by ferrite and very fine pearlite, as usual for this kind of steels.

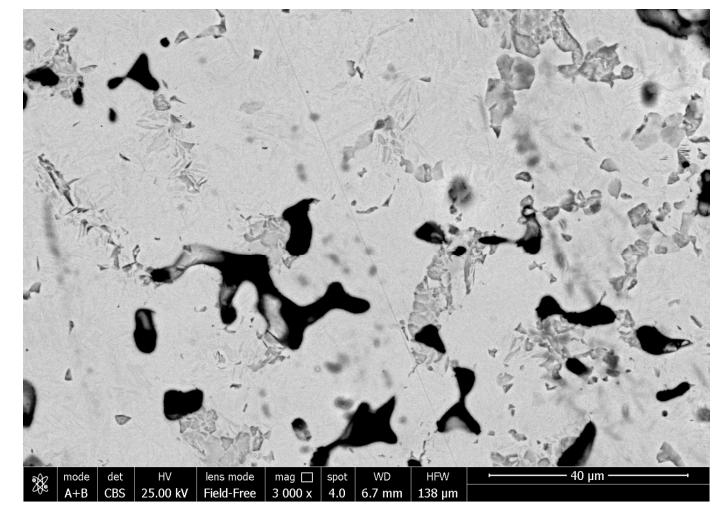

Fig. 5 SEM-BSE Micrograph. Martensiste and upper bainite at mid-height zone

The application of protective atmosphere inhibits decarburization and the microstructure observed is very fine martensite. Oxidation follows decarburization, indeed in the samples 1A, 2A, 1B and 2B a thin layer of oxide is present, as confirmed by SEM-EDS analysis, shown in Fig.8.

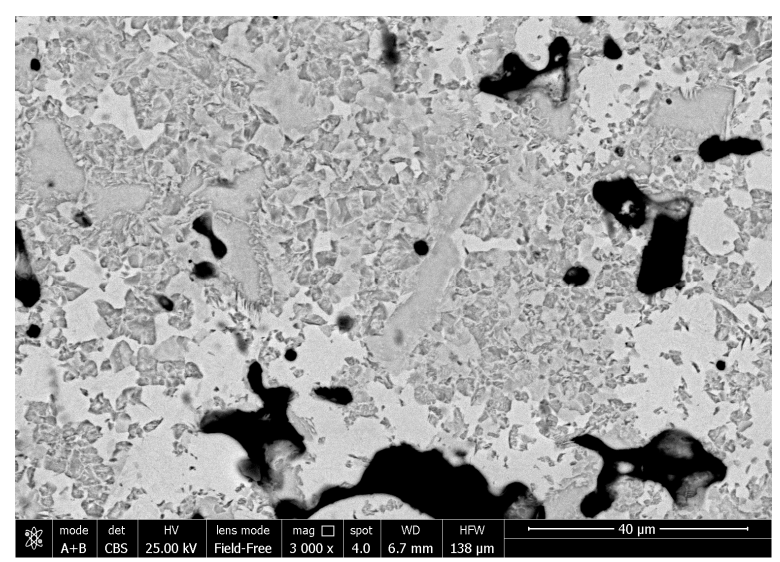

Fig. 6 SEM-BSE Micrograph. Transition zone 


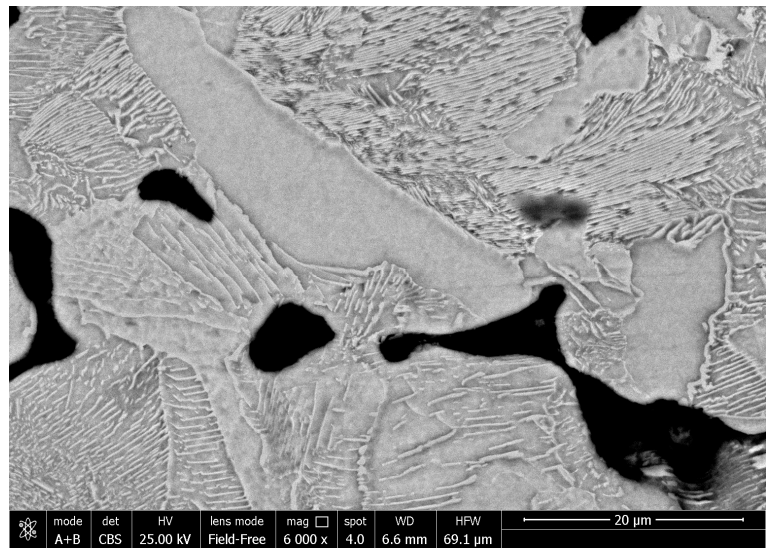

Fig. 7 SEM-BSE Micrograph. Not heat treatment altered zone

Table III lists the basic dimensions, measured by image analysis from optical micrographs of treated transversal sections. $\mathrm{H}$ is the maximum hardening depth (at the center of the figure) and $\mathrm{W}$ is the chord of the segment of circle. It is possible to see that the sample hardened with $8 \mathrm{~mm} / \mathrm{s}$ as laser speed exhibit the highest treated area.

Table III Geometrical data of the hardened zones

\begin{tabular}{|c|c|c|c|}
\hline $\begin{array}{c}\text { Test } \\
\text { code }\end{array}$ & $\begin{array}{c}\text { Height } \\
{[\mathbf{m m}]}\end{array}$ & $\begin{array}{c}\text { Width } \\
{[\mathbf{m m}]}\end{array}$ & $\begin{array}{c}\text { Area } \\
{\left[\mathbf{m m}^{\mathbf{2}}\right]}\end{array}$ \\
\hline 1A & 1.190 & 4.847 & 5.311 \\
\hline 2A & 1.156 & 5.351 & 3.193 \\
\hline 1B & 0.843 & 3.860 & 6.004 \\
\hline 2B & 0.903 & 4.636 & 4.037 \\
\hline A & 1.132 & 4.727 & 5.043 \\
\hline B & 0.698 & 3.749 & 2.519 \\
\hline
\end{tabular}

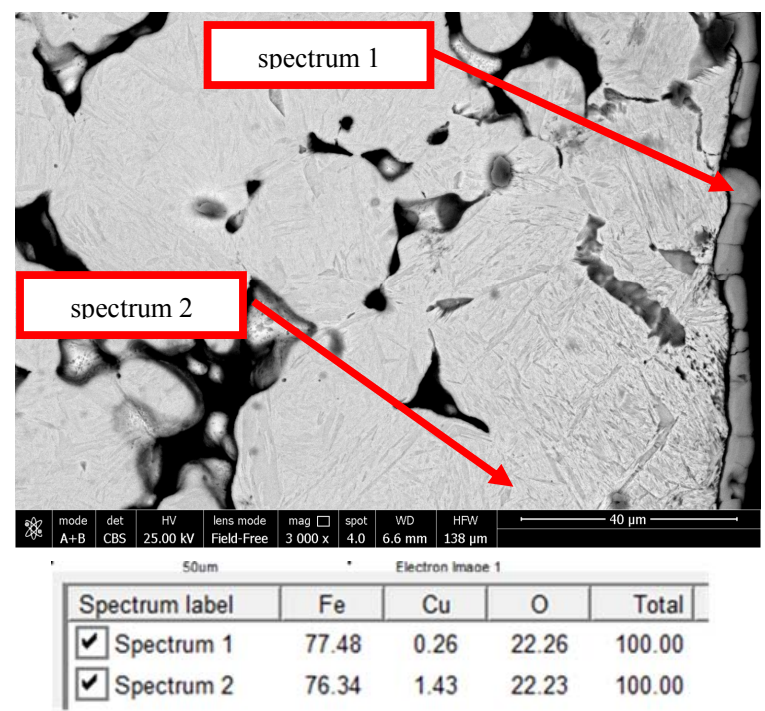

Fig. 8 SEM-BSE Micrograph. Outer oxide layer on the samples treated in air

Figures 9 and 10 show the results of microhardness tests. An increase of the laser speed, from 6 to $8 \mathrm{~mm} / \mathrm{s}$, brings a microhardness increase of more than $20 \%$. An increase of the spot size, from $5 \times 5$ to $7 \times 7 \mathrm{~mm}^{2}$, leads to a microhardness increase of almost $60 \%$. The interaction between laser beam speed and spot size is positive and is responsible for microhardness increase. The positive interaction suggests that operating conditions can be properly combined to get the desired results at a minimum processing cost.

Only the B sample shows an apparently anomalous behavior, with a second microhardness peak at $1.4 \mathrm{~mm}$ distance from the nearest outer surface, compared to the $0.5 \mathrm{~mm}$ hardened zone extension of the remaining samples (Fig 10). This anomalous behavior could be ascribed to possible different heat transfer conditions occurring in the porous zones, compared to denser ones, but a deeper investigation is required on samples manufactured with different sintering conditions and hence densities.

Increasing laser beam speed, in a temperature-controlled laser system, allows to increase microhardness, due to the subsequent higher cooling speed and lower carbon loss. Laser beam speed influences also the depth of hardening: lower laser beam speed, as expected, allows higher penetration hardening, probably due to the longer austenitization time allowed. As a matter of fact, in laser hardening, it is not the cooling rate the most demanding condition (usually selfquenching is so rapid that it brings to full martensite formation), but it is the austenitization time, needed to diffuse the carbon out of the low temperature microstructure (ferrite and pearlite) to form austenite.

In the experimental conditions tested, microhardness profiles are more influenced by laser beam speed than by the laser spot size. Nevertheless, the use of a larger spot size promoted higher hardening depth.

As well-known from the usual results obtained on fully dense steels, the transition zone between the laser affected zone and the base metal exhibits microstructural changes and micro hardness gradient.

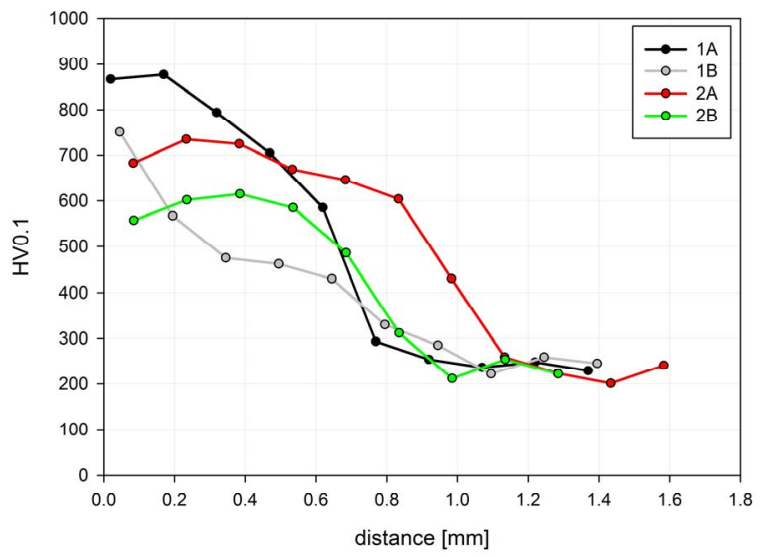

Fig. 9 Microhardness profiles of sample laser treated in air 


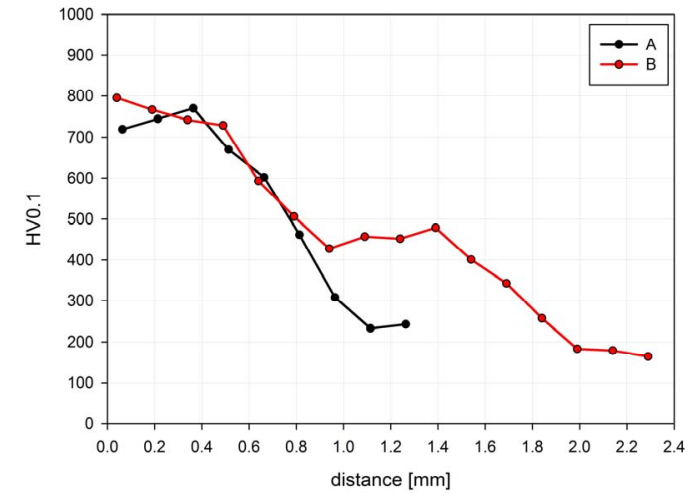

Fig. 10 Microhardness profiles of sample laser treated in argon

In Fig. 11 a representation of the position in which nanoindentations test are carried out is reported. Zone 1 corresponds to surface layer, zone 2 is just below the surface layer, zone 3 is mid-height of treated area, zone 3 is near the transition layer, zone 5 corresponds to transition area and zone 6 is unaffected zone. For each area 10 nanoindentations have been performed and in the graphs reported in Fig. 12 and Fig. 13 the mean values of indentation hardness (HIT) and indentation Modulus (EIT) respectively are shown. HIT values reported in Fig. 12 confirm that in air laser treated samples zone 2 presents the greatest HIT value, due to decarburation/oxidation, and then in decreases inside the section. The transition zone, zone 5 , presents almost the same HIT value of zone 6 (untreated steel). The samples treated in argon, on the contrary, exhibits the maximum HIT value in zone 1, near the surface, because the effective protection to decarburization/oxidation given by the protective gas. In Fig. 12 the indentation Modulus values EIT are visible. All of the analyzed zones present limited differences in EIT values, ascribable to the different microstructure induced by laser heat treatment and on the original samples porosity (indentation modulus is a local, and not global, measurement of elastic modulus). In zone 1 and zone 2 samples laser treated in argon present a greater EIT values than air laser treated because the gas protection to decarburization/oxidation allowed to avoid the formation of compounds with lower elastic modulus.

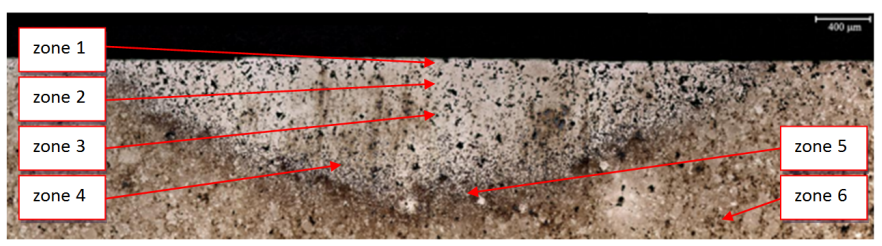

Fig. 11 Positions in which nanoindentation tests are carried out

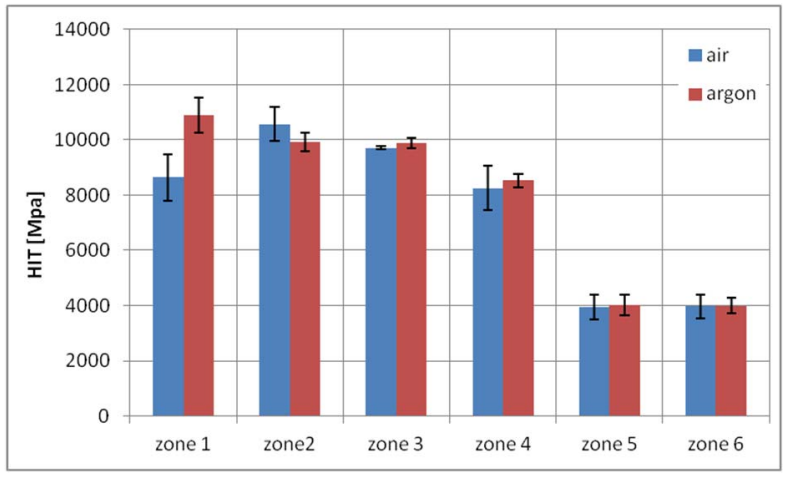

Fig. 12 Nanindentation hardness HIT values

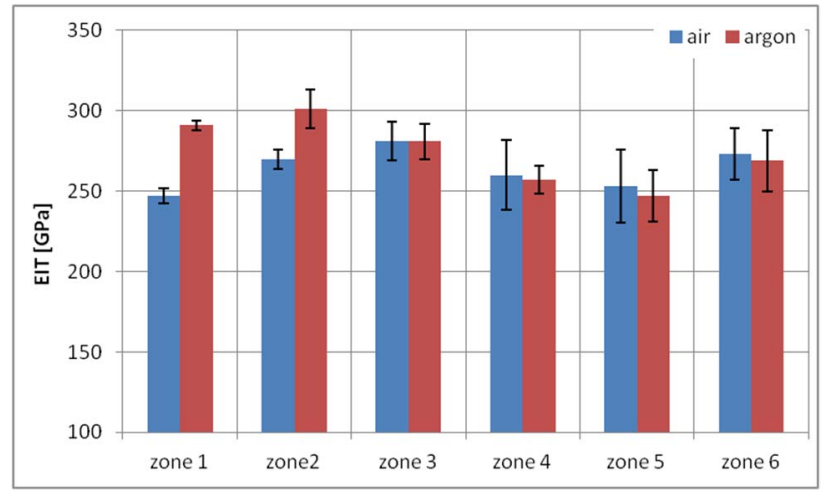

Fig. 13 Nanoindentation Young's Modulus values

\section{CONCLUSIONS}

From the results of analysis it could be concluded that the laser heat treatment forms martensite just below the surface and promotes an increase of microhardness. The application of protective atmosphere leads to a completely martensitic microstructure with high microhardness and high nanomechanical properties. On the contrary, laser treating in air causes a carbon loss and the microstructure near the surface is made of low-carbon martensite. In the studied conditions the most relevant parameter resulted laser beam speed, because, in temperature-controlled operational mode, it influences the cooling rate and, consequently, the microhardness. The lower laser beam speed allowed to reach the highest penetration depth. The research has confirmed the possibility of applying a selective and precise hardening treatment, like Laser Transformation hardening (LHT), to low-alloy and average density $\mathrm{P} / \mathrm{M}$ steel parts.

The positive indications that can be drawn from the results of the research can contribute to expand the use of cost effective $\mathrm{P} / \mathrm{M}$ parts for reliable and demanding applications.

\section{ACKNOWLEDGMENT S}

The authors are grateful to companies Stame Srl (Arosio, $\mathrm{CO}$, Italy) for the preparation of samples 


\section{REFERENCES}

[1] MY.X. Wang, M.F. Yan, B. Li, L.X. Guo, C.S. Zhang, B. Bai, L. Chen, Z. Long, R.W. Li, Surface properties of low alloy steel treated by plasma nitrocarburizing prior to laser quenching process, Optics \& Laser Technology, Volume 67, 2015, Pages 57-64

[2] E. Colombini, R. Sola, G. Parigi, P. Veronesi, G. Poli, Laser Quenching of Ionic Nitrided Steel: Effect of Process Parameters on Microstructure and Optimization, Metall. Mat. Trans. A, Vol. 45, 2014, pp. 5562-5573

[3] D. Panfil. M. Kulka, P. Wach, J. Michalski, D. Prserstacki, Nanomechanical properties of iron nitrides produced on $42 \mathrm{CrMo} 4$ steel by controlled gas nitriding and laser treatment, Journal of alloys and Compounds, vol. 706, 2017, pp. 63-75

[4] Shokrani, V. Dhokia, S. T. Newman, Investigation of the effects of cryogenic machining on the surface integrity in $\mathrm{CNC}$ and milling of $\mathrm{Ti}$ 6Al-4V titanium alloy, Jour. Manuf. Proc., 21, 2016, pp. 172-179

[5] R. Rowshan: "Process Control during Laser Transformation Hardening", PhD Thesis, Miskolc University. Miskolc, Hungaria, 2007

[6] D. Rodziňák, J. Čerňan, R. Zahradníček: "Effect of Laser Hardening on the Properties of PM Steels", Acta Metallurgica Slovaca, Kosice, Vol. 19, 2013, No. 4, p. 282-291
[7] G. F. Bocchini, E. Colombini, G. Parigi, G. Poli, R. Sola, P. Veronesi, Tempra laser di acciai sinterizzati basso-legati, Met. Ital., Volume 108, Issue 11, November 2016, Pages 50-58

[8] E. Colombini, G. F. Bocchini, R. Sola, G. Parigi, G. Poli, P. Veronesi, Laser hardening of homogeneous and inhomogeneous $\mathrm{p} / \mathrm{m}$ steels, Met. Ital., Volume 107, Issue 10, October 2015, Pages 15-24

[9] P. D. Babu, G. Buvanashekaran, K. R. Balasubrama, Experimental Studies on the Microstructure and Hardness of Laser Transformation Hardening of Low Alloy Steel, Transactions of the Canadian Society for Mechanical Engineering,36 (3), 2012, pp. 241-258

[10] G. E. Fougere, L. Riester, M. Ferber, J. R. Weetman, R. W. Siegal, Young's modulus of nanocrystalline Fe measured by nanoindetation, Mat. Sci. Eng. A, A204, 1995, pp. 1-6

[11] H. T. Chen, M. F. Yan, S. S. Fu, Martensite transformation induced by plasma nitrocarburizing on AISI304 austenitic stainless steel, Vacuum, 105,2014 , pp. 33-38

[12] S. K. Balijepalli, I. Colantoni, R. Donnini, S. Kaciulis, M. Lucci, R. Montanari, N. Ucciardello, A. Varone, Modulo elastico della fase S in un acciaio 316L kolsterizzato, La Metallurgia Italiana, vol. 1, 2013, pp. 42-47

[15] R. Sola, R. Giovanardi, G. Parigi, P. Veronesi, A novel method for fracture toughness evaluation of tool steels with post-tempering cryogenic treatment, Metals, vol. 75, 2017, pp. 1-9. 